\title{
Medievalista
}

Online

$26 \mid 2019$

Número 26

\section{Diana Pelaz Flores, Rituales líquidos. El significado del agua en el ceremonial de la corte de Castilla (ss. XIV-XV)}

\section{Víctor Muñoz Gómez}

\section{(2) OpenEdition}

\section{Journals}

Edición electrónica

URL: http://journals.openedition.org/medievalista/2710

DOI: 10.4000/medievalista.2710

ISSN: 1646-740X

Editor

Instituto de Estudos Medievais - FCSH-UNL

Edición impresa

Fecha de publicación: 1 junio 2019

\section{Referencia electrónica}

Víctor Muñoz Gómez, «Diana Pelaz Flores, Rituales líquidos. El significado del aqua en el ceremonial de la corte de Castilla (SS. XIV-XV) », Medievalista [En línea], 26 | 2019, Publicado el 27 julio 2019, consultado el 23 septiembre 2020. URL : http://journals.openedition.org/medievalista/2710; DOI : https://doi.org/ 10.4000/medievalista.2710

\section{(c) (1) (8)}

Mediavalista está licenciado com uma Licença Creative Commons - Atribuição-NãoComercial 4.0 Internacional. 
Título / Title: PELAZ FLORES, Diana - Rituales líquidos. El significado del agua en el ceremonial de la corte de Castilla (ss. $X I V-X V$ ). Murcia: Editum-Ediciones de la Universidad de Murcia, 2017. ISBN 978-84-16551-76-7 (142 páginas).

Autor(es) / Author(s): Víctor Muñoz Gómez

Afiliação institucional (Unidade de Investigação, Faculdade e Departamento, Universidade, Código Postal, Cidade, País): Sección Geografía e Historia Departamento de Geografía e Historia / Instituto de Estudios Medievales y Renacentistas, Universidad de La Laguna, 38200, San Cristóbal de La Laguna (S.C. de Tenerife), España Email Institucional / Institutional email: vmunozgo@ull.edu.es Fonte: Medievalista [Em linha]. Direc. Bernardo Vasconcelos e Sousa. Lisboa: IEM. Disponível em: http://www2.fcsh.unl.pt/iem/medievalista/MEDIEVALISTA26/gomez2610.html ISSN: 1646-740X

Data recepção do artigo / Received for publication: 23 de janeiro de 2019 


\section{Recensão / Review: PELAZ FLORES, Diana - Rituales líquidos. El significado del agua en el ceremonial de la corte de Castilla (ss. XIV-XV). Murcia: Editum-Ediciones de la Universidad de Murcia, 2017. ISBN 978-84-16551-76-7 (142 páginas)}

\section{Víctor Muñoz Gómez}

El año 2017 fue especialmente prolífico para Diana Pelaz Flores, uno de los nuevos valores del medievalismo hispánico a partir de sus meritorios trabajos acerca del estudio del papel de la reina en la Castilla del siglo XV a partir de la aplicación de perspectivas de género al análisis histórico. Fruto, fundamentalmente, de su inteligente tesis doctoral, la cual se dedicó al tema arriba señalada, fue la publicación de nada menos que tres monografías en las que se desgranan los aspectos relativos a las formas de ejercicio del poder de las reinas, su entorno relacional y el valor simbólico y representativo de su figura en la Corona de Castilla durante la Baja Edad Media a partir del estudio de caso de las reinas consortes del monarca Juan II, María de Aragón e Isabel de Portugal ( $L a$ casa de la reina en la Corona de Castilla (1418-1496). Valladolid: Universidad de Valladolid; Poder y representación de la reina en la Corona de Castilla (1418-1496). Salamanca: Junta de Castilla y León; Reinas consortes. Las reinas de Castilla entre los siglos $X I-X V$. Madrid: Sílex Ediciones). Junto a estos volúmenes y algunos otros trabajos, un cuarto libro redondea su prolífica producción en ese año, justamente dedicada a la otra línea de investigación que la autora ha desarrollado prioritariamente y que mucho tiene que ver con la primera ya citada, ligada a los estudios sobre género y poder real femenino: la del estudio de simbolismo del agua en el ceremonial regio castellano del final de la Edad Media.

Rituales líquidos, justamente, viene a reunir hasta cuatro estudios breves de Diana Pelaz que se centran en esta temática, desarrollados al amparo del proyecto de investigación 
"El agua en el imaginario de la Castilla bajomedieval" (HAR2012-32264) en el seno del Grupo de Investigación Consolidado de la Universidad de Valladolid "Agua, espacio y sociedad en la Edad Media”, dirigido por la profesora María Isabel del Val Valdivieso. El objetivo del libro expresado por la autora no es otro que profundizar en los usos y significación del agua en el ámbito cortesano de la Castilla bajomedieval en términos representativos y ceremoniales. Así, el prefacio que introduce el libro sirve para desarrollar estos propósitos, de modo que el estudio de los rituales y ceremonias de la corte de Castilla en que el agua intervino permitirán profundizar en su sentido como elemento dotado de propiedades purificadoras y de limpieza, tanto del cuerpo físico como del simbólico de la persona del monarca. Estas nociones, enmarcadas tanto en el sustrato ideológico cristiano de la época como en la mentalidad aristocrática dominante $\mathrm{y}$, sobre todo, los discursos de afirmación del poder regio dan lugar así a una comprensión monográfica del agua como objeto simbólico central en la representación de la identidad y el poder de la monarquía y sus titulares en Castilla que, al fin, busca contribuir a esa línea de estudios políticos y culturales, ya fructífera dentro del medievalismo español.

Tras un breve, pero muy correcto capítulo introductorio en el que se presenta el estado de la cuestión acerca de la investigación desarrollada en España y buena parte de Europa en los últimos veinticinco años sobre el agua y su lugar simbólico en el mundo medieval, ligado a su valor sacramental, funciones litúrgicas y de representación ceremonial del poder, comienza propiamente la materia de análisis tratada en el libro. Tres capítulos lo componen, en los cuales se abordan monográficamente tres cuestiones referidas a ese lugar ocupado por el agua en lo que la autora entiende como las principales ceremonias cortesanas en que este elemento jugaba un papel de especial relevancia en Castilla. Así, el primero de ellos se preocupa de analizar la concepción de la limpieza del soberano, tanto desde el punto de vista de la higiene cotidiana como desde aquel otro del baño ritual estipulado en los rituales de coronación. El segundo afronta el uso del agua, la gestualidad y la semiótica tramada alrededor de la etiqueta de la mesa regia. El tercero y último, finalmente, se concentra en una peculiar conexión entre el valor purificador e integrador del agua bautismal y la traslación de este rito de paso para el otorgamiento de los oficios heráldicos en la corte y su propia jerarquización interna entre persevantes, farautes y reyes de armas. El libro concluye con un epílogo en 
que se sintetizan algunas conclusiones sobre las consideraciones higiénicas, simbólicas y culturales de la ritualidad cortesana castellana en que el agua intervenía y que fueron desplegándose a lo largo de los capítulos previos.

Así, es muy interesante cómo la autora presenta, por lo que se refiere al baño regio, la doble realidad del carácter privado y restringido al público del aseo del rey, dirigido a mantener tanto su salud física como la propia condición mayestática que ha de ejercer su cuerpo político, y del valor ceremonial abierto otorgado a las ceremonias de baño por inmersión ligadas a la coronación. La conexión de este ceremonial con el sentido sacro de purificación bautismal y otorgación de potencias de origen sagrado que legitiman el ejercicio del poder, amén de aquella otra con las ceremonias de investidura caballeresca, resultan muy acertadamente apuntadas. El valor comunicativo del acto de "dar agua" en el desarrollo de los banquetes regios también es subrayado, apreciándose cómo este hecho permitía marcar una jerarquía que reafirmaba la más alta dignidad del rey sobre el resto de los comensales. De nuevo, la higiene en la mesa es certeramente interpretada a partir de su lectura sacramental, de modo que buena parte de la etiqueta del banquete conecta con los ritos eucarísticos. Por su parte, las ceremonias de nombramiento de los oficiales de armas de la corte, en los que no faltan las analogías respecto al bautismo a partir de la imposición del nombre al heraldo, el mismo bautismo con agua y a imposición de las sobrevestas con armas y divisas, todo ello oficiado por el rey a quien el oficial representará, pasando a participar de la representación del cuerpo político de la monarquía, son descritas con gran coherencia. De nuevo la conexión en su uso con la que le corresponde en las ceremonias de investidura caballeresca - y de deposición caballeresca, que la autora también trata - es bien palpable. Merece igualmente la pena citar la atención dedicada por Diana Pelaz a la valoración simbólica de cada uno de los objetos envueltos en este conjunto de ceremonias junto al agua (aguamaniles, copas, toallas, etc.), por la importancia de no dejar de lado estos testimonios materiales del discurso y el lenguaje de representación del poder sobre el que se está discurriendo en el libro.

Cada uno de los capítulos está compuesto a partir de un sólido soporte bibliográfico y teórico. El acceso a la literatura doctrinal bajomedieval (con autores que van desde don Juan Manuel hasta Gonzalo Fernández de Oviedo, pasando Enrique de Villena, Alonso 
de Palencia o "El Tostado", entre otros), a los tratados donde se apuntaban aspectos reguladores relativos a las ceremonias estudiadas (Las Partidas, fundamentalmente) y a textos cronísticos castellanos bajomedievales donde son expuestas es muy meritorio. En cualquier caso, es cierto igualmente que los aportes de evidencias sobre los temas analizados, aunque no dejan de aparecer, son a menudo escasos y menos sistemáticos de lo que se podría desear. Aunque el recurso a comparaciones y analogías bien fundadas a partir de fuentes de otros reinos hispánicos (como las Ordinacions catalanoaragonesas) y de ejemplos extraídos de bibliografía referentes a otros ámbitos cortesanos del Occidente medieval son más que apropiadas, da la impresión de que puede haber lugar a seguir profundizando a la hora de llenar de evidencias castellanas al bien construido y consistente discurso elaborado por Diana Pelaz sobre el lugar del agua en el ceremonial regio castellano.

Hay que ser, en cualquier caso, conscientes de lo extraordinario y poco frecuentes que resultan las menciones a las temáticas trabajadas en los capítulos del libro en las fuentes castellanas bajomedievales. Acaso una exploración más intensiva en fuentes documentales como las de Archivo General de Simancas podría aportar un mayor número de referencias acerca de los oficiales cortesanos implicados en los hechos $\mathrm{y}$ momentos ceremoniales o en las características materiales de esos objetos destinados al consumo de bebidas y la higiene corporal y de mesa, el cual seguramente la autora podrá ir desarrollando en futuras publicaciones.

Es cierto, en fin, que estas impresiones pueden provenir de que, en buena medida, el libro se articula como una colección de estudios prácticamente autónomos entre sí alrededor de la temática común de las funciones simbólicas del agua en el contexto cortesano de la Castilla bajomedieval, dotados de lógica interna y sentido propio aun de forma independiente los unos de los otros. Su publicación conjunta, con todo, es un hecho a celebrar. En conclusión, puede afirmarse que la autora ha abierto camino, elaborando con gran acierto un marco general de comprensión del medio acuático en el lenguaje simbólico de representación del poder regio en Castilla. Éste podrá ser enriquecido y completado en futuros trabajos, ya que ha aportado la base para la continuación de esta línea de investigación para otros historiadores y para ella misma. Es, por tanto, una lectura más que recomendable para los estudiosos de los lenguajes 
representativos del poder en el mundo bajomedieval en general y en la Corona de Castilla en particular, a partir de la cual esperamos que Diana Pelaz nos pueda seguir ofreciendo nuevos y valiosos frutos sobre esta área de trabajo tan bien conectada con sus estudios sobre el poder regio femenino.

\section{COMO CITAR ESTE ARTIGO}

\section{Referência electrónica:}

MUÑOZ GÓMEZ, Víctor - "PELAZ FLORES, Diana - Rituales líquidos. El significado del agua en el ceremonial de la corte de Castilla (ss. XIV-XV). Murcia: Editum-Ediciones de la Universidad de Murcia, 2017. ISBN 978-84-16551-76-7 (142 páginas)". Medievalista 26 (Julho-Dezembro 2019). [Em linha] [Consultado dd.mm.aaaa]. Disponível em http://www2.fcsh.unl.pt/iem/medievalista/MEDIEVALISTA26/gomez2610.html ISSN 1646-740X.

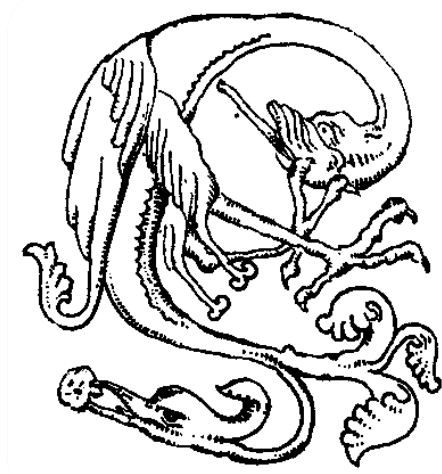

